\title{
COPPER ACCUMULATION IN VINEYARD SOILS FROM NEMEA, GREECE
}

\author{
Kelepertzis E. ${ }^{1}$, Massas I. ${ }^{2}$, Fligos G. ${ }^{1}$, Panagiotou M. ${ }^{2}$ and Argyraki A. ${ }^{1}$ \\ ${ }^{1}$ Department of Geology and Geoenvironment, University of Athens, Panepistimiopolis, 15784, \\ Athens, Greece, kelepert@geol.uoa.gr,giorgos_fligos@yahoo.com,argyraki@geol.uoa.gr \\ ${ }^{2}$ Department of Natural Resources and Agricultural Engineering, Agricultural University of \\ Athens, 75 Iera Odos St., 11855, Athens, Greece, massas@aua.gr, stud609027@aua.gr
}

\begin{abstract}
We present for the first time the extent and magnitude of $\mathrm{Cu}$ accumulation in calcareous vineyard soils from Nemea, Greece, as result of intensive application of Cu-based fungicidal sprays. Surface $(0-20 \mathrm{~cm})$ soil samples were collected from 40 vineyard plots covering the whole agricultural region of Nemea devoted to viticulture. In 20 randomly selected vineyards, we also collected soil at $50 \mathrm{~cm}$ depth. Major soil properties were determined $(\mathrm{pH}$, electrical conductivity, organic carbon and equivalent calcium carbonate contents, particle size distribution). Copper concentrations in Nemea vineyard soils (33.1 - $\left.291 \mathrm{mg} \mathrm{kg}^{-1}\right)$ were similar to those reported in the soils of vineyards in other parts of Europe. Copper has migrated down the soil profile since the levels at $50 \mathrm{~cm}$ depth are higher than the known background concentrations, probably as result of soil disturbance by tillage practices. We did not find differences in $\mathrm{Cu}$ availability between the surface and deep soil samples after applying the DTPA chemical extraction. The DTPA-extracted Cu concentrations were largely dependent on the total soil $\mathrm{Cu}$ content. The excessive application of $\mathrm{Cu}$-based fungicides should be avoided with the aim to ensure that $\mathrm{Cu}$ accumulation does not reach levels that may inhibit plant growth.
\end{abstract}

Keywords: chemical extractions, heavy metals, soil contamination, agricultural activities.

\section{Пєрі́ $\eta \psi \eta$}

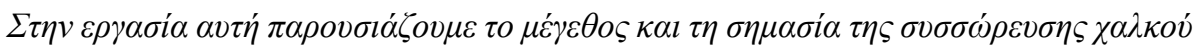

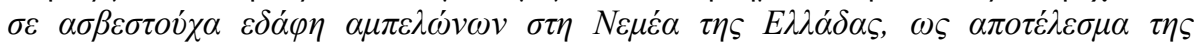

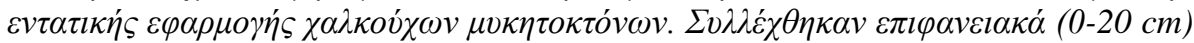

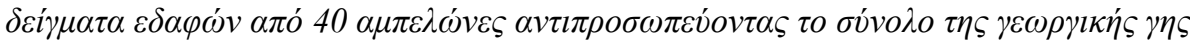

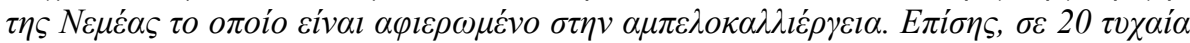

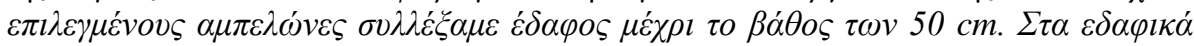

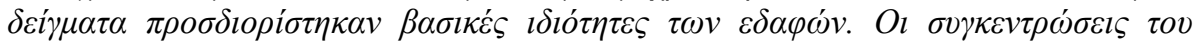

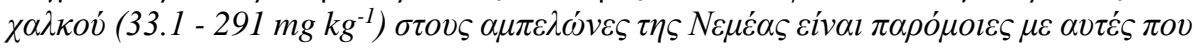

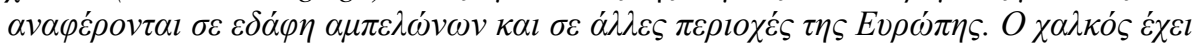

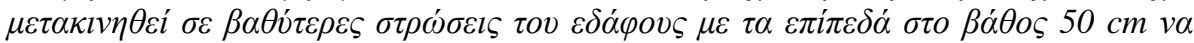

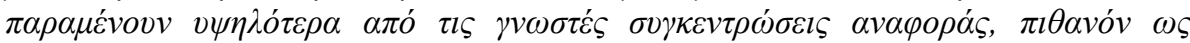

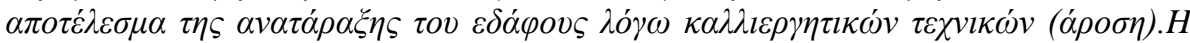

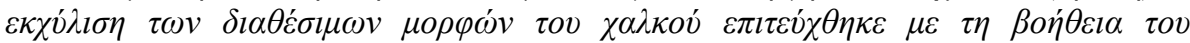

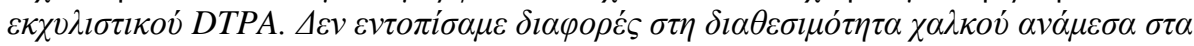




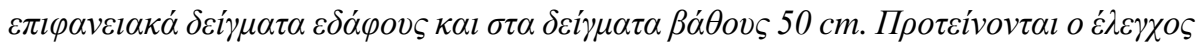



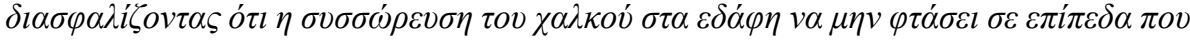

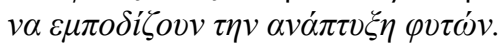

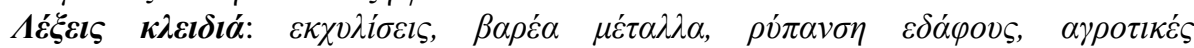

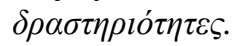

\section{Introduction}

Since the end of the $19^{\text {th }}$ century, the intensive application of copper $(\mathrm{Cu})$-based fungicides in vineyards to fight vine fungal diseases, such as downy mildew caused by Plasmopara viticola, has resulted to increased $\mathrm{Cu}$ concentrations in the receiving soils (Komárek et al., 2010). The wash-off of $\mathrm{Cu}$ from the vine leaves, the deposition of the senescent leaves and the accidental spills of the fungicides are the major source processes of $\mathrm{Cu}$ to the vineyard soils. However, the $\mathrm{Cu}$ accumulation in the soil over the years is the result of its strong fixation to soil organic matter, $\mathrm{Fe}$ - and $\mathrm{Mn}$ (hydr)oxides and clay minerals (Komárek et al., 2008 and Pietrzak and McPhail, 2004). This geochemical behavior combined with the neutral-alkaline soil $\mathrm{pH}$ of most of vineyard soil (Mackie et al., 2012) do not favor the migration of $\mathrm{Cu}$ throughout the soil profile. As a result, a decrease in $\mathrm{Cu}$ concentrations with increasing depth has been reported, and $\mathrm{Cu}$ commonly reaches background levels within 40-50 cm depth (Deluisa et al., 1996 and Pietrzak and McPhail, 2004). Referring to the chemical methods used in the laboratory to determine the $\mathrm{Cu}$ content in vineyard soil, the aqua regia extraction is frequently applied, especially in the European studies, but with low correlation with the phytoavailability of this element. For that reason, a variety of single stage chemical extractions has been proposed for mimicking the processes that operate at the soil-plant interface providing more useful information for the fraction of $\mathrm{Cu}$ that is available for plant uptake (Kelepertzis et al., 2015).

In Greece, the favorable calcareous substrate and the Mediterranean climatic conditions have allowed the wide spread of viticulture since the early historic years. In North Peloponnese, the region of Nemea has enjoyed a long tradition of intensive grapevine growing for the production of its indigenous Agiorgitiko red wine variety. In this area, $\mathrm{Cu}$-based fungicides, such as copper sulfate $\left(\mathrm{CuSO}_{4}\right)$, have been extensively applied to the vineyards, and as a result there is a high potential risk for soil contamination with $\mathrm{Cu}$. An investigation regarding the $\mathrm{Cu}$ concentration levels in agricultural soils from different regions of Greece, including some vineyard soils located in Nemea, has previously been undertaken (Vavoulidou et al., 2005). Nevertheless, this study was based on a reduced set of samples without delineating the magnitude of $\mathrm{Cu}$ accumulation throughout this region and without investigating the potential $\mathrm{Cu}$ migration in deeper soil layers. The aim of the present survey was to assess the extent and magnitude of $\mathrm{Cu}$ accumulation in Nemea vineyard soils by using the aqua regia and diethylene triamine pentaacetic acid (DTPA) chemical extractions and to investigate the potential for the soil to retain $\mathrm{Cu}$ at greater depths.

\section{Materials and Methods}

\subsection{Soil sampling and preparation}

Soil samples were collected during May and June 2015 from a total of 40 vineyard plots evenly distributed throughout the Nemea agricultural region devoted to grapevine production (Fig. 1). We specifically followed the recommendations given by Wightwick et al. (2006) who suggested the collection of one composite sample from as many vineyards in a region as possible instead of collecting many samples from fewer vineyards. In each vineyard, soil samples were collected from the surface soil $(20 \mathrm{~cm}$ depth) from the middle row in the vineyard. Within this row, soil was collected from locations one-fourth, halfway and three-fourths of the way down the row, and the sub-samples were mixed in order to constitute a representative composite sample from each vineyard. Following the conclusions reached by Pietrzak and McPhail (2004) and Mirlean et al. (2007) who 
claimed that $\mathrm{Cu}$ concentrations are higher at the vines than between the vine lines, we collected the surface soil samples within $30 \mathrm{~cm}$ of the vine line instead of collecting soil from the middle of the row. This soil sampling strategy was accomplished with the aim to detect the highest concentrations of accumulated $\mathrm{Cu}$ in the studied vineyard soil. Additionally, at 20 randomly selected vineyards, we collected soil at a depth of $50 \mathrm{~cm}$ using a soil auger. The samples were air dried at $45^{\circ} \mathrm{C}$ for three days, sieved through a $2 \mathrm{~mm}$ plastic sieve and well homogenised. Representative portions obtained by quartation were further sieved through a $100-\mu \mathrm{m}$ sieve and stored in room temperature.

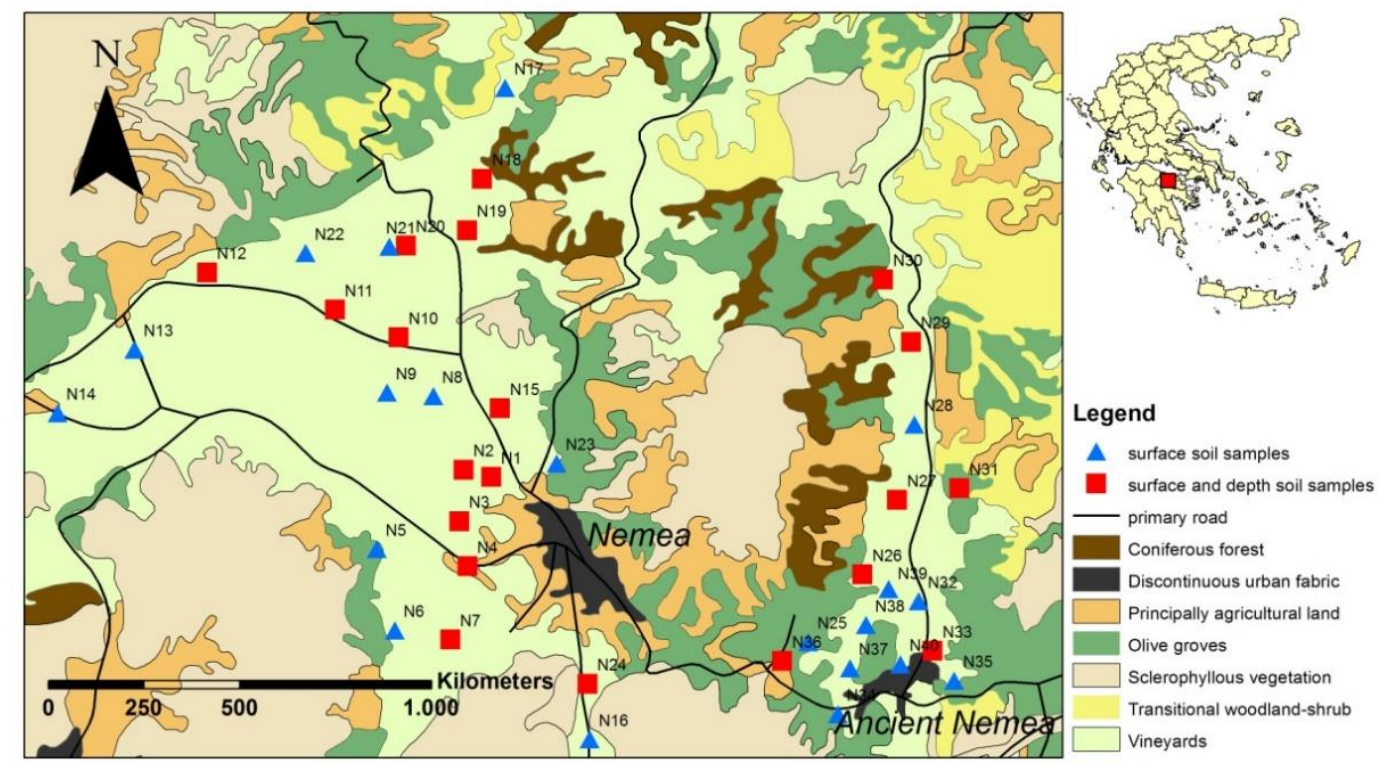

Figure 1 - Land use map of the area according to the CORINE database showing the location of the investigated vineyard plots.

\subsection{Soil analysis}

Soil $\mathrm{pH}$ and electrical conductivity were determined using a 1:1 ratio (w/v) of soil and deionised water based on the $<2 \mathrm{~mm}$ sample fraction. Total organic carbon (TOC) was determined on the < $100 \mu \mathrm{m}$ fraction according to the method described by Walkley and Black (1934). Particle size distribution in the sand, silt and clay fractions was determined using the hydrometer sedimentation method. The equivalent calcium carbonate content was determined by $\mathrm{HCl}$ attack. The applied chemical extractions were performed on the $<100 \mu \mathrm{m}$ fraction. Copper was extracted from soil samples using the aqua regia attack $\left(\mathrm{HNO}_{3} / \mathrm{HCl}, 1: 3\right)$ at the Acme Analytical Laboratories of Canada and $\mathrm{Cu}$ concentrations were measured using Inductively Coupled Plasma-Mass Spectrometry (ICP-MS). Hereafter and for simplicity reasons, the $\mathrm{Cu}$ concentrations determined by this method will be referred to as total. The availability of $\mathrm{Cu}$ was evaluated by the DTPA extraction because of its effectiveness in neutral to alkaline soils (Lindsay and Norvell, 1978). Concentrations of $\mathrm{Cu}$ in the DTPA extracts were determined by flame atomic absorption spectrometry.

\section{Results}

Basic physico-chemical properties and extracted $\mathrm{Cu}$ concentrations of the studied vineyard surface soils are given in Table 1. The strong influence of the carbonate bedrock on soil chemistry is reflected by the alkaline soil $\mathrm{pH}$ (median 7.8) and the high eq. $\mathrm{CaCO}_{3}$ content (up to 68.9\%). The soils exhibit a low TOC content (median $1.34 \%$, max 1.99\%) and a wide variation in the electrical conductivity values ranging from 256 to $1150 \mu \mathrm{S} / \mathrm{cm}$. The texture in most of the vineyard-devoted soils is characterised by the predominance of the clay fraction (median 44.3\%), which is expected 
given that the weathering of carbonate rocks result to soil parent materials that give rise to soils with a fine texture.

Table 1 - Descriptive statistics of the analysed soil properties and $\mathrm{Cu}$ concentrations extracted by the aqua regia and DTPA chemical extractions for the surface soil samples $(n=40)$.

\begin{tabular}{|l|l|l|l|l|}
\hline Variable & Mean & Median & Minimum & Maximum \\
\hline $\mathrm{pH}$ & 7.8 & 7.8 & 7.4 & 8.1 \\
\hline Electrical Conductivity $(\mu \mathrm{S} / \mathrm{cm})$ & 484 & 465 & 256 & 1150 \\
\hline Sand $(\%)$ & 26.7 & 25.5 & 12.8 & 51.8 \\
\hline Silt $(\%)$ & 31.4 & 31.6 & 20.6 & 39.6 \\
\hline $\mathrm{Clay}(\%)$ & 41.9 & 44.3 & 24.6 & 58.6 \\
\hline $\mathrm{CaCO}_{3}(\%)$ & 42.7 & 41.0 & 9.8 & 68.9 \\
\hline $\mathrm{TOC}(\%)$ & 1.35 & 1.34 & 0.68 & 1.99 \\
\hline $\mathrm{Cu}($ aqua regia), mg kg-1 & 116 & 111 & 33.1 & 291 \\
\hline $\mathrm{Cu}$ DTPA, $\mathrm{m} \mathrm{kg}^{-1}$ & 22.6 & 21.3 & 3.2 & 59.4 \\
\hline
\end{tabular}

The total $\mathrm{Cu}$ concentrations in the surface vineyard soils varied from 33.1 to $291 \mathrm{mg} \mathrm{kg}^{-1}$ with a median value of $111 \mathrm{mg} \mathrm{kg}^{-1}$. The average $\mathrm{Cu}$ content observed in the $0-20 \mathrm{~cm}$ soil layer by the DTPA extraction was $22.6 \mathrm{mg} \mathrm{kg}^{-1}$, with a maximum concentration of $59.4 \mathrm{mg} \mathrm{kg}^{-1}$. No significant differences could be found in $\mathrm{Cu}$ variation with depth $(\mathrm{p}>0.05$, one way ANOVA) based on the results from the 20 vineyard plots where soil samples were collected from both the surface and deeper soil horizons. An inspection of the variation in $\mathrm{Cu}$ amounts as a function of soil depth (Figure $2 \mathrm{a}$ and $2 \mathrm{~b}$ ) indicates that the classical expected decrease with depth is not evident for all the vineyards; for some vineyards, the $\mathrm{Cu}$ concentrations (for both metal forms) can remain either the same (e.g. for the investigated vineyards coded as N7, N11 and N18) or considerably increased (e.g. for the vineyards coded as N15 and N10).

(a)

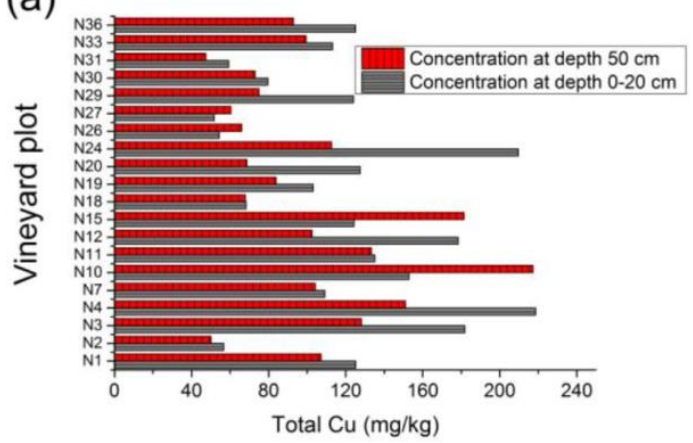

(b)

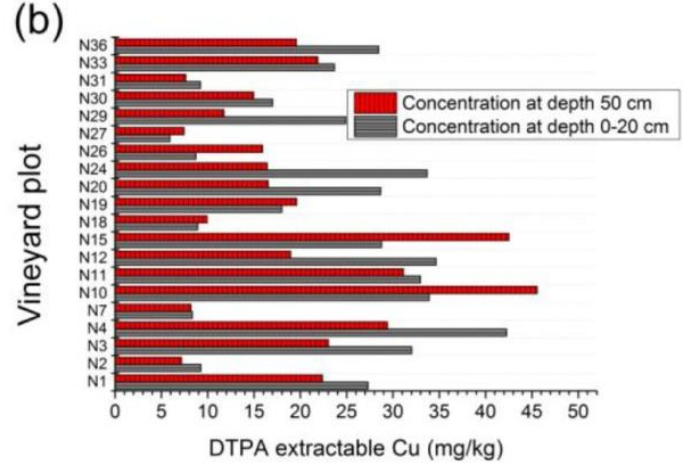

Figure 2 - Total (a) and DTPA (b) extractable $\mathrm{Cu}$ concentrations at two depths $(0-20 \mathrm{~cm}$ and $50 \mathrm{~cm}$ ) in 20 vineyard soils from Nemea.

\section{Discussion}

The vineyard soils from Nemea presented elevated $\mathrm{Cu}$ concentrations when compared to the world average $\mathrm{Cu}$ content of $20 \mathrm{mg} \mathrm{kg}^{-1}$ for non-contaminated soils (Kabata-Pendias and Pendias, 2001). Copper has a tendency to be excluded from carbonate rocks, sandstones and calcareous shales (Kabata-Pendias and Pendias, 2001). Since the local geology is characterised by the presence of such rocks we consider that weathering and erosion has minimum contribution to the observed soil 
$\mathrm{Cu}$ enrichment. Moreover, $\mathrm{Cu}$ concentrations in background uncultivated soil samples from the adjacent Argolida area, which is characterized by occurrences of similar rock types and therefore similar soil parent material, ranged from 17.24 to $42.81 \mathrm{mg} \mathrm{kg}^{-1}$ (Kelepertzis, 2014). Such data clearly demonstrate that the source of $\mathrm{Cu}$ in the studied vineyard soils could be attributed to the application of $\mathrm{Cu}$-based fungicides. Furthermore, the low contents of $\mathrm{Zn}$ and $\mathrm{Cd}$ in the studied soils (data not presented in this study) provide further evidence that the fungicide treatments should be regarded as the principal source for the established soil $\mathrm{Cu}$ enrichment. These elements are typical tracers of fertilizer and manure application in agricultural soils (Kelepertzis, 2014).

Our results are comparable to those reported from studies in vineyards within other European countries. In particular, the total $\mathrm{Cu}$ concentrations in the present study are consistent with those found in the soils of vineyards in Italy (mean $130 \mathrm{mg} \mathrm{kg}^{-1}$, Deluisa et al., 1996), France (mean 99 mg kg${ }^{-1}$, Brun et al., 1998) and NW Iberian Peninsula (mean $163 \mathrm{mg} \mathrm{kg}^{-1}$, Fernández-Calviño et al., 2009). The levels of concentrations tend to be lower than those found in our study for the Australian vineyards (Wightwick et al., 2006) and for vineyards from the Czech Republic (Komárek et al., 2008), probably due to the lower average annual usage of $\mathrm{Cu}$-based fungicides. On the contrary, $\mathrm{Cu}$ concentrations in Brazilian vineyards and in vineyards from Champagne area, France, can reach up to $3200 \mathrm{mg} / \mathrm{kg}^{-1}$ and $1500 \mathrm{mg} / \mathrm{kg}^{-1}$ respectively, because of the exceptionally high volumes of fungicides that are needed in areas with greater humidity and precipitation for diminishing downy mildew attacks (Mirlean et al., 2007).

Interestingly, a wide variation in the $\mathrm{Cu}$ concentrations is observed for the soils of the studied vineyards since the values are fluctuating from 33.1 to $291 \mathrm{mg} \mathrm{kg}^{-1}$ (Table 1). In general, differences in the $\mathrm{Cu}$ concentrations among vineyards from the same region could be ascribed to variation in soil properties, topography and $\mathrm{Cu}$ application history. In the present study and in line with findings by Vavoulidou et al. (2005) and Deluisa et al. (1996), no significant correlation was found between the analysed soil parameters and the $\mathrm{Cu}$ concentrations, probably due to the relatively narrow range of values of the soil properties. Only a weak positive correlation was found between the organic content and the $\mathrm{Cu}$ total concentrations $(r=0.37, \mathrm{p}=0.02)$ indicative though of $\mathrm{Cu}$-humic complexes as a result of the long history of $\mathrm{Cu}$ application and the humification processes. The dispersion of $\mathrm{Cu}$-enriched soil particles via runoff and soil erosion could be an influencing factor for the observed variation in $\mathrm{Cu}$ concentrations; nonetheless, the majority of the studied vineyards is exclusively located in the plain area (approximately $300 \mathrm{~m}$ a.s.l.), and as a result the topography can be reasonably regarded to have a relatively minor influence on the extent of $\mathrm{Cu}$ accumulation. According to Mackie et al. (2012) the effect of topography on $\mathrm{Cu}$ accumulation in vineyard soil is rather unclear and probably is masked when other determinants are taken into consideration. We speculate that the vineyard age is the main parameter that determines $\mathrm{Cu}$ concentrations since some vineyards in the Nemea region have been cultivated for more than 100 years. Previous studies have demonstrated that as vineyards age they are subjected to prolonged periods of fungicide treatments resulting to a more pronounced $\mathrm{Cu}$ accumulation (Romić et al., 2014; Rusjan et al., 2007). The Bordeaux mixture $\left[\mathrm{CuSO}_{4}+\mathrm{Ca}(\mathrm{OH})_{2}\right]$ has been widely used since the end of $19^{\text {th }}$ century in various countries, for example in Croatia (Romić et al., 2014) and in France (McBride et al., 1981), but we have not been able to verify the exact time period that this material was first used in the area of Nemea.

Copper accumulates mainly in the topsoil following fungicidal sprays application because of its complexation with organic matter and affinity for Fe oxyhydroxides and decreases with depth (Komárek et al., 2010); this pattern was also seen for almost half of the vineyard plots where a soil sample from a deeper soil horizon was obtained (Fig. 2a). However and contrary to the general concession that $\mathrm{Cu}$ eventually returns to natural levels at a maximum depth of $-50 \mathrm{~cm}$, the studied vineyards at this particular depth exhibited a median soil $\mathrm{Cu}$ concentration of $96.1 \mathrm{mg} \mathrm{kg}^{-1}(n=20)$ which is considerably higher than the background concentrations (Kelepertzis, 2014). Furthermore, in some cases $\mathrm{Cu}$ concentrations remain either the same or even increase down to $50 \mathrm{~cm}$ depth (Fig. 2a) pointing out to a specific process that results to $\mathrm{Cu}$ migration deeper into the soil profile. 
Considering the alkaline $\mathrm{pH}$ of the investigated vineyard soils that does not favor the mobility of $\mathrm{Cu}$, leaching should be excluded. Moreover, the predominance of clay fraction provides plethora of cation exchange sites for $\mathrm{Cu}$ adsorption and neither promotes the opening of transport routes of water for the removal of minerals and soil particles nor shows any cracks during the dry summer period due to minor water application in vines; as a result, the process of $\mathrm{Cu}$ eluviation in these soils should be restricted. Soil disturbance by tillage should be the key reason for the redistribution of $\mathrm{Cu}$-enriched particles within the profile (Romic et al., 2014) resulting to the significant accumulated $\mathrm{Cu}$ levels at $50 \mathrm{~cm}$ depth.

In the present study, we applied the DTPA chemical extraction for assessing the $\mathrm{Cu}$ availability. This chemical reagent uses a strong ligand that allows $\mathrm{Cu}$ desorption from the solid matrix through the mechanism of complexation. It was originally developed for the determination of $\mathrm{Cu}, \mathrm{Zn}, \mathrm{Fe}$ and Mn deficiency in neutral and alkaline soils (Lindsay and Norvell, 1978), and is has been frequently adopted for assessing $\mathrm{Cu}$ availability in vineyard soils (examples given by Brun et al., 1998; Deluisa et al., 1996 and Romić et al., 2014). The average available $\mathrm{Cu}$ concentrations were almost identical for both the surface and deep soil samples (18.7 and $22.6 \mathrm{mg} \mathrm{kg}^{-1}$, respectively) and were quite similar with the mean value of $15.4 \mathrm{mg} \mathrm{kg}^{-1}$ reported by Vavoulidou et al. (2005) for vineyard soils from the same area. The availability ratios that were calculated by dividing the $\mathrm{Cu}$ amounts obtained by the DTPA extraction over the total soil content, were almost the same for both the surface soils and the soils collected at $50 \mathrm{~cm}$ depth (Fig. 3). Such data further support the evidence for soil disturbance in Nemea area, as result of vineyard soil tilling by the local landowners. In the case of vineyard soils from Czech Republic (Komárek et al., 2008) and Italy (Deluisa et al., 2006), the $\mathrm{Cu}$ availability, both in terms of the actual values and relative to the total content, was significantly higher in the superficial soil layer, perhaps as a result of specific local cultivation tillage implements that are restricted to the surface soil. In addition, an excellent positive correlation coefficient $(r=0.94$, $\mathrm{p}=0.000$ ) was found between the DTPA-extractable $\mathrm{Cu}$ and the respective total $\mathrm{Cu}$ content for the investigated soil samples from Nemea, in agreement with findings by Deluisa et al. (1996) and Romić et al. (2014). Linear regression analysis demonstrated that the available $\mathrm{Cu}$ concentrations can be accurately predicted by the corresponding total content $\left(\mathrm{Cu}_{\mathrm{DTPA}}=-2.82+0.220 \mathrm{Cu}_{\text {total }}, R_{\text {adj }}^{2}\right.$ $=87.4 \%$ ). Considering that the available $\mathrm{Cu}$ is part of the total $\mathrm{Cu}$ concentration, this strong correlation indicates a common source of both metal forms, which is the intensive fungicide application in the vineyards of Nemea area.

Copper is an essential micronutrient for plants and is involved in several metabolic processes. Despite its essentiality, excess $\mathrm{Cu}$ in soil has phytotoxic effects, including plant growth retardation and leaf chlorosis (Kabata Pendias and Pendias, 2001). The range of $\mathrm{Cu}$ concentrations determined in this study is not expected to cause phytotoxicity considering both monocotyledon and dicotyledon plants (toxicity thresholds are 18-537 mg kg-1 and 36-698 mg kg-1, respectively) (Oorts, 2013). In addition and based on the threshold of human dietary toxicity for $\mathrm{Cu}\left(10 \mathrm{mg} \mathrm{kg}^{-1}\right)$, the critical concentrations of total and available (DTPA) $\mathrm{Cu}$ in the soil were found to be 430 and $269 \mathrm{mg} \mathrm{kg}^{-1}$ for pakchoi, 608 and $313 \mathrm{mg} \mathrm{kg}^{-1}$ for celery, and 835 and $339 \mathrm{mg} \mathrm{kg}^{-1}$ for Chinese cabbage, respectively (Yang et al., 2002). The total and DTPA-extracted $\mathrm{Cu}$ concentrations as well as the alkaline $\mathrm{pH}$ values that determined in the investigated soils do not support potential phytotoxicity problems in the agricultural region of Nemea. 


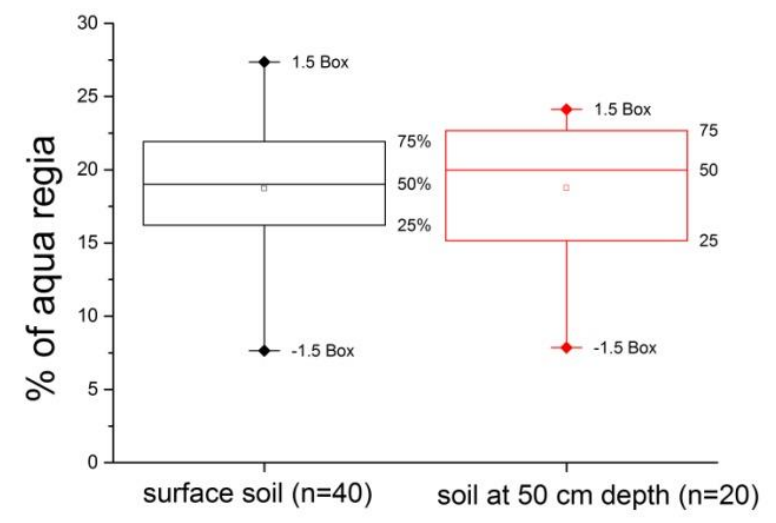

Figure 3 - Ratio of the Cu concentrations extracted by the DTPA method relative to the total soil content in the vineyard soils from Nemea.

\section{Conclusions}

Similar to agricultural areas around the world where Cu-based fungicides have been extensively applied, the calcareous vineyard soils from Nemea display elevated $\mathrm{Cu}$ concentrations that are much higher than the background levels. A wide range of $\mathrm{Cu}$ concentrations has been determined and the extent of $\mathrm{Cu}$ accumulation could be linked to the age of individual vineyard and the associated $\mathrm{Cu}$ application history, but such information cannot be easily acquired. Copper has been migrated through the soil profile, at least to a $50 \mathrm{~cm}$ depth, and this pattern is attributed to soil disturbance by tillage agricultural practices. As a consequence, the availability of $\mathrm{Cu}$, as was evaluated by the DTPA extraction, does not demonstrate differences between the surface and the deeper soil samples. The DTPA-extracted $\mathrm{Cu}$ concentrations correlate significantly with the respective $\mathrm{Cu}$ total content in the soil indicating a common source of both metal forms in the soils of the area. Although the alkaline nature of the studied vineyard soils is certainly a limiting factor of plant uptake, the application rates of $\mathrm{Cu}$-based fungicidal sprays should be reduced in order $\mathrm{Cu}$ accumulation does not reach levels that can inhibit plant growth.

\section{Acknowledgments}

The Municipality of Nemea is acknowledged for financial support covering the geochemical analyses at the ACME Analytical Laboratories.

\section{References}

Brun, L.A., Maillet, J., Richarte, J., Herrmann, P. and Remy, J.C., 1998. Relationships between extractable copper, soil properties and copper uptake by wild plants in vineyard soils, Environmental Pollution, 102, 151-161.

CORINE land cove, 1994, Technical Guide Office for Official Publications of the European Communities, Luxembourg (1994).

Deluisa, A., Giandon, P., Aichner, M., Bortolami, P., Bruna, L., Lupetti, A., Nardelli, F. and Stringari, G., 1996. Copper pollution in Italian vineyard soils, Communications in Soil Sciences and Plant Analysis, 27, 1537-1548.

Fernández-Calviño, D., Nóvoa-Muñoz, J.C., Díaz-Raviña, M. and Arias-Estévez, M., 2009. Copper accumulation and fractionation in vineyard soils from temperate humid zone (NW Iberian Peninsula), Geoderma, 153, 119-129. 
Kabata-Pendias, A. and Pendias, H., 2001. Trace elements in soils and plants, Third edition, CRC Press, NW.

Kelepertzis, E., 2014. Accumulation of heavy metals in agricultural soils of Mediterranean: Insights from Argolida Basin, Peloponnese, Greece, Geoderma, 221-222, 82-90.

Kelepertzis, E., Paraskevopoulou, V., Argyraki, A., Fligos, G. and Chalkiadaki, O., 2015. Evaluation of single extraction procedures for the assessment of heavy metal extractability in citrus agricultural soil of a typical Mediterranean environment (Argolida, Greece), Journal of Soils and Sediments, in press.

Komárek, M., Száková, J., Rohošková, M., Javorská, H., Chrastný, V. and Balík, J., 2008. Copper contamination of vineyard soils from small wine producers: A case study from the Czech Republic, Geoderma, 147, 16-22.

Komárek, M., Čadková, E., Chrastny, V., Bordas, F. and Bollinger, J.-C., 2010. Contamination of vineyard soils with fungicides: A review of environmental and toxicological aspects, Environment International, 36, 138-151.

Lindsay, W.L. and Norvell, W.A., 1978. Development of a DTPA soil test for zinc, iron, manganese and copper, Soil Science Society of America Journal, 42, 421-428.

Mackie, K.A., Müller, T. and Kandeler, E., 2012. Remediation of copper in vineyards - A mini review, Environmental Pollution, 167, 16-26.

McBride, M., Tiller, K. and Merry, R., 1981. Copper in soils and plants, Academic Press, Sydney.

Mirlean, N., Roisenberg, A. and Chies, J.O., 2007. Metal contamination of vineyard soils in wet subtropics (southern Brazil), Environmental Pollution, 149, 10-17.

Oorts, K., 2013. Copper. In: Alloway, B.J., ed., Heavy metals in soils, Trace metals and metalloids in soils and their bioavailability, $3^{\text {rd }}$ edition, Springer Dordrecht Heidelberg.

Pietrzak, U. and McPhail, D.C., 2004. Copper accumulation, distribution and fractionation in vineyards soils of Victoria, Australia, Geoderma, 122, 151-166.

Romić, M., Matijević, L., Bakić, H. and Romić, D., 2014. Copper accumulation in vineyard soils: Distribution, fractionation and bioavailability assessment. In: Hernandez-Soriano, M.C., ed., Environmental Risk Assessment of Soil Contamination, doi: 10.5772/57086.

Rusjan, D., Strlič, M., Pucko, D. and Korošec-Koruza, Z., 2007. Copper accumulation regarding the soil characteristics in Sub-Mediterranean vineyards of Slovenia, Geoderma, 141, 111-118.

Vavoulidou, E., Avramides, E.J., Papadopoulos, P., Dimirkou, A., Charoulis, A. and Konstantinidou-Doltsinis, S., 2005. Copper content in agricultural soils related to cropping systems in different regions of Greece, Communications in Soil Science and Plant Analysis, $36,759-773$.

Walkley, A. and Black, I.A., 1934. An examination of the Degtjareff method for determining soil organic matter, and a proposed modification of the chromic acid titration method, Soil Science, 37, 29-37.

Wightwick, A., Mollah, M., Smith, J. and MacGregor, A., 2006. Sampling considerations for surveying copper concentrations in Australian vineyard soils, Australian Journal of Soil Research, 44, 711-717.

Wightwick, A.M., Mollah, M.R., Partington, D.L. and Allinson, G., 2008. Copper fungicide residues in Australian vineyard soils, Journal of Agricultural and Food Chemistry, 56, 2457-2464.

Yang, X-E., Long, X-X., Ni, W-Z., Ye, Z-Q., He, Z-L., Stoffella, P.J. and Calvert, D.V., 2002. Assessing copper thresholds for phytotoxicity and potential dietary toxicity in selected vegetable crops, Journal Environmental Science and Health Part B, B37, 625-635. 